\title{
QUALIDADE DE VIDA DO DOADOR APÓS TRANSPLANTE HEPÁTICO INTERVIVOS
}

\author{
Júlio Cezar Uili COELHO ${ }^{1}$, Mônica Beatriz PAROLIN', Giorgio Alfredo Pedroso BARETTA², \\ Silvania Klug PIMENTEL ${ }^{1}$, Alexandre Coutinho Teixeira de FREITAS $^{1}$ e Daniel COLMAN $^{3}$
}

RESUMO - Racional - A qualidade de vida do doador após transplante hepático intervivos ainda não foi avaliada em nosso meio. Objetivo - Avaliar a qualidade de vida do doador após transplante hepático intervivos. Métodos - De um total de 300 transplantes hepáticos, 51 foram de doadores vivos. Doadores com seguimento menor do que 6 meses e os que não quiseram participar do estudo foram excluídos. Os doadores responderam a um questionário de 28 perguntas abordando os vários aspectos da doação, sendo também avaliados dados demográficos e clínicos dos mesmos. Resultados - Trinta e sete doadores aceitaram participar do estudo. Destes, 32 eram parentes de primeiro ou de segundo grau do receptor. O esclarecimento sobre o caráter voluntário da doação foi adequado para todos pacientes. Apenas um (2\%) não doaria novamente. A dor pós-operatória foi pior do que o esperado para 22 doadores (59\%). O retorno às atividades normais ocorreu em menos de 3 meses para 21 doadores (57\%). Vinte e um doadores (57\%) tiveram perda financeira com a doação devido a gastos com medicamentos, exames, transporte ou perda de rendimentos. Trinta e três (89\%) não tiveram modificação ou limitação na sua vida após a doação. Os aspectos mais negativos da doação foram a dor pós-operatória e a presença de cicatriz cirúrgica. A maioria das complicações pós-operatória foi resolvida com o tratamento clínico, mas complicações graves ou potencialmente fatais ocorreram em dois pacientes. Conclusões - A maioria dos doadores apresentou boa recuperação e retornou completamente as suas atividades normais poucos meses após a doação. O aspecto mais negativo da doação foi a dor pós-operatória.

DESCRITORES - Qualidade de vida. Transplante de fígado. Obtenção de órgãos. Doadores vivos.

\section{INTRODUÇÃO}

Com a expressiva melhora dos resultados do transplante hepático nas últimas décadas, número elevado de pacientes com hepatopatia crônica e aguda passou a procurar os serviços de transplante ${ }^{(10,18,26)}$. Conseqüentemente, o tempo em lista de espera e a mortalidade de pacientes aguardando este procedimento aumentaram exponencialmente nos últimos anos ${ }^{(21,26)}$. A escassez de doadores cadavéricos estimulou a realização de transplante hepático intervivos, inicialmente em crianças e posteriormente em adultos ${ }^{(6,7,20)}$. Desde o primeiro transplante hepático intervivos, realizado por RAIA et al. ${ }^{(20)}$ na Universidade de São Paulo em 1989, o número desse tipo de transplante vem crescendo em vários países. No Brasil, o número de transplante hepático intervivos aumentou de 6 em 1997 para 177 em $2003^{(21)}$.

No transplante intervivos, é essencial a preservação da saúde do doador. Este sempre é pessoa saudável, sem problemas médicos significantes ${ }^{(19)}$. Para o sucesso do programa de transplante intervivos é fundamental que as complicações dos doadores sejam mínimas e que a mortalidade seja nula ou muito próxima a ela. Além do mais, o transplante deve alterar muito pouco a qualidade de vida do doador, permitindo rapidamente o retorno completo a todas atividades usuais $^{(12,24)}$. A qualidade de vida do doador após o transplante hepático intervivos ainda não foi avaliada no nosso meio. O objetivo do presente estudo foi avaliar a qualidade de vida do doador após este tipo de transplante no Hospital de Clínicas da Universidade Federal do Paraná e no Hospital Nossa Senhora das Graças, Curitiba, PR.

\section{MÉTODOS}

De um total de 300 transplantes hepáticos realizados no Hospital de Clínicas da Universidade Federal do Paraná e Hospital Nossa Senhora das Graças, Curitiba, PR, pela mesma equipe médica, 51 foram transplantes realizados com doadores vivos. Foram excluídos do presente estudo os doadores com seguimento pós-

\footnotetext{
${ }^{1}$ Serviço de Transplante Hepático do Hospital de Clínicas da Universidade Federal do Paraná (HC-UFPR); ${ }^{2}$ Departamento de Cirurgia do Aparelho Digestivo do HC-UFPR ${ }^{3}$ Serviço de Anestesia do HC-UFPR, Curitiba, PR.

Endereço para correspondência: Dr. Júlio C. U. Coelho - Rua Bento Viana, 1140 - apt. 2202 - 80240-110 - Curitiba, PR. E-mail: juliocoelho@bbs2.sul.com.br
} 
operatório menor do que 6 meses e os que não quiseram participar do estudo.

Todos os doadores foram submetidos a avaliação médica completa para excluir doenças significantes. Doenças transmissíveis foram excluídas através de exames laboratoriais padronizados. Ressonância magnética e arteriografia foram realizadas para determinar o tamanho volumétrico do fígado e estudar a anatomia das vias biliares, artéria hepática e da veia porta e hepáticas. Biopsia hepática foi realizada para determinar a presença de esteatose hepática somente nos indivíduos com índice de massa corpórea superior a $30 \mathrm{~kg} / \mathrm{m}^{2}$ ou com exame de imagem sugestivo dessa condição. Os vários aspectos da doação, inclusive de evolução pós-operatória foram completamente esclarecidos por, pelo menos, três membros da equipe médica (um cirurgião, um hepatologista e um médico residente) em datas diferentes. Os doadores foram submetidos a avaliação psicológica e social. Após obtenção de consentimento informado, foi obtida autorização do Ministério Público de todos pacientes. Para os doadores não aparentados do receptor, foi obtida autorização judicial, em conformidade com a legislação brasileira atual.

Os doadores responderam completamente a um questionário pessoalmente ou via ligação telefônica a um entrevistador. O questionário continha 28 perguntas abordando os vários aspectos da doação: avaliação e cuidados pré-operatórios e evolução e complicações pós-operatórias (Figura 1). As perguntas avaliavam aspectos orgânicos, psicológicos e sociais. As alterações orgânicas e psicossociais atribuídas pelo paciente à doação foram registradas. Opiniões dos doadores sobre a orientação e esclarecimento pré e pósoperatórios e sobre doação de órgãos foram consideradas. $\mathrm{O}$ entrevistador era um médico com formação completa em cirurgia do sistema digestório e em transplante de órgãos, que não tinha participado dos transplantes e nos cuidados dos pacientes. O protocolo de estudo computadorizado também foi revisado para se obter dados demográficos e clínicos dos doadores.

Os dados foram analisados estatisticamente usando o programa JMP, versão 501 (SAS Institute, EUA). As variáveis foram analisadas através do teste Qui-quadrado. Os valores foram expressos em média \pm desvio padrão e intervalo de confiança de $95 \%$ (IC 95\%). Foram considerados estatisticamente significativos valores de $P$ menores ou iguais a $0,05(5 \%)$.

\section{RESULTADOS}

Dos 51 doadores, 37 foram incluídos no estudo. Os dados demográficos desses doadores são mostrados na Tabela 1. A maioria dos doadores $(n=32 ; 86 \%)$ era parente de primeiro ou segundo grau do receptor. Todos os quatro doadores não-familiares (11\%) eram indivíduos que participavam ativamente de atividades religiosas. Seis doadores foram submetidos a excisão do segmento lateral esquerdo (segmento II e III) e 31 do lobo hepático direito (segmentos V a VIII). $\mathrm{O}$ tempo médio de afastamento das atividades normais no pré-operatório foi de 9 dias (IC $95 \%$ de 6 a 26 dias) e pósoperatório foi de 87 dias (IC $95 \%$ de 70 a 164 dias). A duração média de internação foi de 6 dias (IC $95 \%$ de 4 a 13 dias). O seguimento médio dos doadores foi de $1,88 \pm 1,46$ ano (IC $95 \%$ de 1,6 e 2,8 anos).

A sobrevida dos receptores foi de $77 \%$ em 1 ano e de $70 \%$ em 3 anos e 5 anos, determinada pela curva de Kaplan-Meier.

A principal motivação para a doação foi salvar a vida do receptor em $22(59 \%)$, vontade de ajudar o receptor em 5 (14\%), diminuir o sofrimento do receptor em $4(11 \%)$, vínculo familiar com o receptor em 3 (8\%) e outros motivos em $3(8 \%)$.

Apenas três doadores (8\%) referiram que o esclarecimento pré-doação foi insuficiente. Esses doadores mencionaram que gostariam de ter tido mais informações sobre os resultados do transplante, dois deles sobre os riscos da doação e um sobre a dor e sofrimento pós-operatório.

Todos referiram que foram bem esclarecidos sobre o caráter voluntário da doação e nenhum sentiu qualquer forma de pressão para realizá-la. Apenas um (2\%) mencionou que não doaria novamente. Este foi o único paciente que apresentou complicações pós-operatórias graves, insuficiência de múltiplos órgãos e sistemas secundários à úlcera duodenal perfurada. Dois (5\%) não recomendariam a doação intervivos. Todos eram favoráveis e recomendariam a doação de órgãos post mortem.

Os doadores atribuíram nota média de $8 \pm 2$ (IC 95\% de 7 a 8,6) para a avaliação geral do pós-operatório em escala de 0 a 10 , sendo 0 o pior e 10 o melhor. Quanto ao sofrimento pós-operatório, os doadores atribuíram nota de $7 \pm 2,3$ (IC $95 \%$ de 6 a 7,7) em escala de 0 a 10 , sendo 0 o menor e 10 o maior.

Em relação à expectativa pré-operatória, a evolução e recuperação pós-operatórias foram piores do que o esperado para $19(51 \%)$ dos doadores, melhores para $15(41 \%)$ e iguais ao esperado para $3(8 \%)$. Quanto à dor pós-operatória, $22(59 \%)$ tiveram mais dor do que o esperado, $9(24 \%)$ menos e $6(16 \%)$ igual ao esperado.

O retorno ao trabalho e ou às atividades escolares ocorreu em menos de 2 meses para 14 (38\%), 2 a 3 meses para 7 (19\%), de 3 a 6 meses para $7(19 \%)$ e após 6 meses para $8(22 \%)$. Somente um doador (3\%) com 10 meses de pós-operatório ainda não retornou ao trabalho. Este foi o único doador que apresentou complicação pós-operatória grave.

Quanto ao suporte financeiro para ajudar a custear os gastos durante o período de avaliação pré-operatória e o período de recuperação pós-operatória, 5 (14\%) receberam auxílio da família, 4 (11\%) diretamente do receptor, 4 (11\%) do INSS, 4 (11\%) do empregador, $7(19 \%)$ de outras fontes e $13(35 \%)$ não receberam auxílio. O total de 21 doadores (57\%) referiu perda financeira com a doação devido a gastos com medicamentos, exames, transporte ou perda de rendimentos.

A maioria dos doadores $(n=33 ; 89 \%)$ não observou modificação ou limitação na sua vida. Dos quatro $(11 \%)$ pacientes que referiram modificação ou limitação, dois $(5 \%)$ relatavam limitação física, um (3\%) intolerância alimentar e um (3\%) piora 


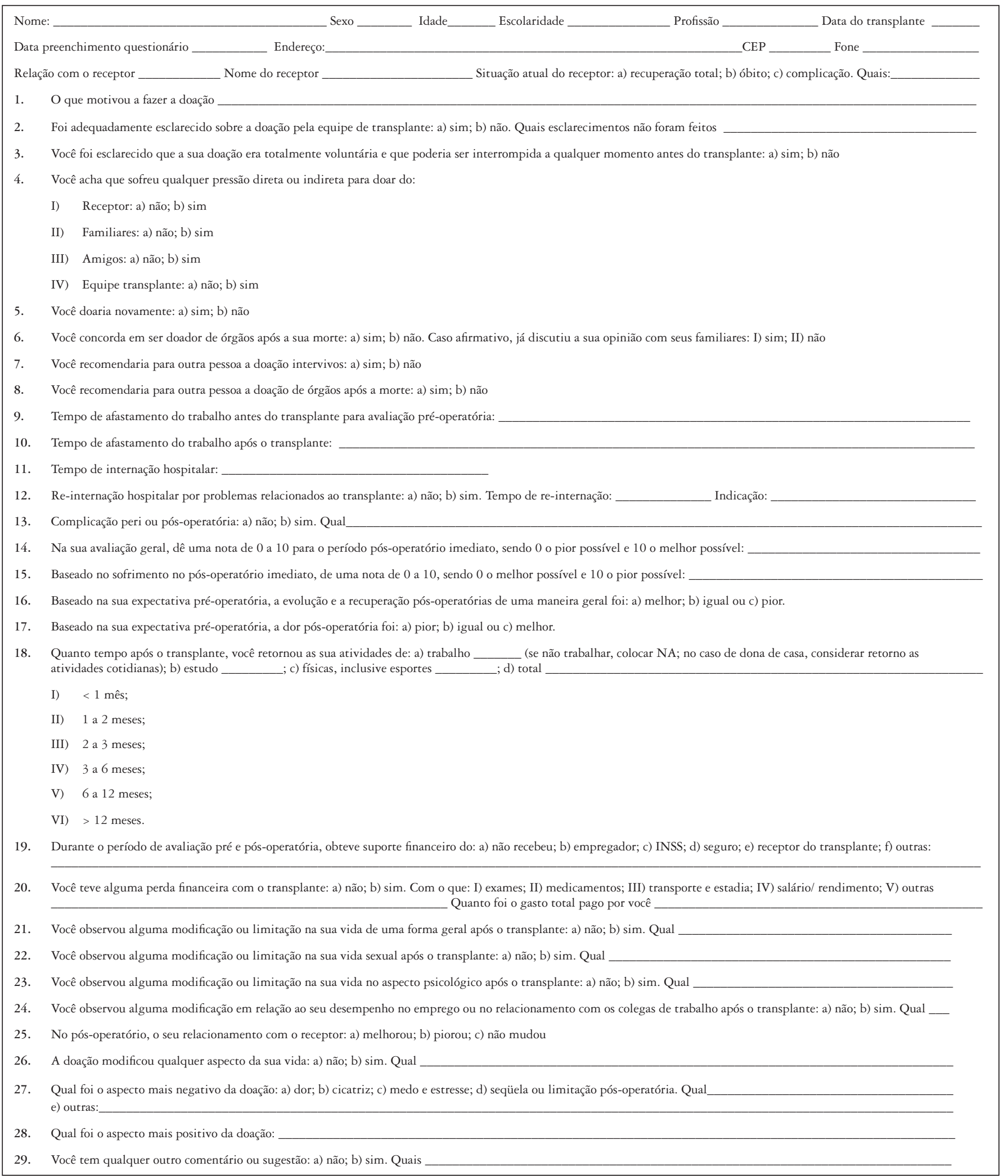

FIGURA 1 - Questionário sobre complicações e impacto na qualidade de vida do doador de transplante hepático intervivo no período pós-transplante 
TABELA 1 - Aspectos demográficos dos doadores

\begin{tabular}{|c|c|}
\hline Característica & $\mathrm{n}$ \\
\hline Número de doadores & 37 \\
\hline Idade & $34 \pm 11$ anos \\
\hline \multicolumn{2}{|l|}{ Sexo } \\
\hline masculino & $28(76 \%)$ \\
\hline feminino & $9(24 \%)$ \\
\hline \multicolumn{2}{|l|}{ Escolaridade } \\
\hline primário & $11(30 \%)$ \\
\hline secundário & $17(46 \%)$ \\
\hline terciário & $9(24 \%)$ \\
\hline \multicolumn{2}{|l|}{ Relação com o receptor } \\
\hline filhos & $11(25 \%)$ \\
\hline pais & $8(22 \%)$ \\
\hline irmãos & $5(14 \%)$ \\
\hline cônjuge & $4(11 \%)$ \\
\hline amigos & $4(11 \%)$ \\
\hline primos & $1(3 \%)$ \\
\hline sobrinhos & $1(3 \%)$ \\
\hline avós & $1(3 \%)$ \\
\hline tios & $1(3 \%)$ \\
\hline cunhados & $1(3 \%)$ \\
\hline \multicolumn{2}{|l|}{ Segmentos excisados } \\
\hline segmentos II e III & $6(16 \%)$ \\
\hline segmentos V a VIII & $31(84 \%)$ \\
\hline Tempo de afastamento pré-operatório (dias) & $9,2 \pm 12$ \\
\hline Duração da internação (dias) & $6 \pm 4,7$ \\
\hline Tempo de afastamento pós-operatório (dias) & $87 \pm 71$ \\
\hline Seguimento pós-operatório (ano) & $1,88 \pm 1,46$ \\
\hline
\end{tabular}

TABELA 2 - Complicações pós-operatórias dos doadores

\begin{tabular}{lcc}
\hline Complicação & $\mathrm{n}^{*}$ & $\%$ \\
\hline Náuseas e vômitos & 14 & 37,8 \\
Infecção da ferida operatória & 8 & 21,6 \\
Diarréia & 3 & 8,1 \\
Derrame pleural & 3 & 8,1 \\
Coleção intra-abdominal & 2 & 5,4 \\
Atelectasia pulmonar & 2 & 5,4 \\
Fístula biliar & 2 & 5,4 \\
Úlcera duodenal & 2 & 5,4 \\
Pneumonia & 2 & 5,4 \\
Pneumotórax & 1 & 2,7 \\
Hérnia incisional & 1 & 2,7 \\
Trombose da veia porta & 1 & 2,7 \\
Disfunção de múltiplos órgãos e sistemas & 1 & 2,7 \\
\hline
\end{tabular}

*Alguns pacientes tiveram mais do que uma complicação

do relacionamento com o marido. Modificação ou limitação do aspecto psicológico foi relatada por seis $(16 \%)$ doadores.

O relacionamento com o receptor não modificou em 20 (55\%) doadores, melhorou em $14(39 \%)$, piorou em apenas 1 (3\%) e não pode ser avaliado em $2(5 \%)$, por morte precoce do receptor.

$\mathrm{O}$ aspecto mais negativo da doação foi a dor para $16(43 \%)$ doadores, cicatriz cirúrgica para $6(16 \%)$, o mal resultado para o receptor em $4(11 \%)$, medo e estresse para $1(2,7 \%)$ e seqüela para o doador em $1(2,7 \%)$. Nove (24\%) não relataram nenhum aspecto negativo. $\mathrm{O}$ aspecto mais positivo foi a recuperação do receptor em 19 (51\%) dos casos, sensação de ter ajudado em $12(32 \%)$, melhora da auto-estima em $3(8 \%)$ e melhora do relacionamento com o receptor em $1(2,7 \%)$. Dois pacientes negaram qualquer aspecto positivo da doação.

As complicações pós-operatórias estão evidenciadas na Tabela 2. As complicações mais freqüentes foram de menor relevância e resolveram com o tratamento clínico. Náuseas e vômitos foram de curta duração, geralmente menos do que 24 horas, na maioria dos doadores.

A complicação mais grave foi a de um doador que apresentou úlcera duodenal perfurada no $3^{\circ}$ dia de pósoperatório. Apesar do paciente ter sido operado com poucas horas de evolução da complicação, evoluiu com septicemia e insuficiência de múltiplos órgãos e sistemas. Este doador recebeu alta hospitalar após 2 meses de internação hospitalar, com hemiparesia secundária à isquemia cerebral.

Outro doador apresentou trombose da veia porta, complicação potencialmente grave, possivelmente devido à anomalia congênita de trifurcação e não bifurcação deste vaso. O paciente teve boa evolução, sem nenhuma outra intercorrência. Ultra-sonografia com Doppler colorido realizada no $3^{\circ}$ mês de pós-operatório evidenciou recanalização da veia.

\section{DISCUSSÃO}

O número de transplante de órgãos com doadores vivos aumentou expressivamente nos últimos $\operatorname{anos}^{(5,17,22,27)}$. Dados dos Estados Unidos, Europa e Ásia evidenciam que quase todos doadores ficaram satisfeitos com a decisão de terem doado parte do fígado e apresentaram excelente recuperação, retornando as suas atividades normais sem restrições e sem seqüelas em poucos meses após o transplante ${ }^{(12,24)}$. O presente estudo mostrou resultados similares. A maioria dos doadores retornou a todas as suas atividades, inclusive de trabalho e escolares, em menos de 3 meses do transplante. Entretanto, dois quintos dos pacientes desta série retornaram as atividades normais somente 3 meses após a doação. Este dado é importante no preparo de potenciais doadores, que devem ser orientados sobre a possibilidade de um período de recuperação prolongado.

A quase totalidade dos pacientes desta casuística ficou satisfeita com o esclarecimento pré-operatório sobre todo processo de doação, inclusive sobre as informações sobre dor, complicações e evolução pós-operatórias. Quesito de fundamental importância ética se refere ao caráter voluntário da doação. Em serviços onde o presente trabalho foi desenvolvido, este ponto foi enfatizado por vários membros da equipe durante o processo de avaliação pré-operatória. Esclareceu-se que qualquer forma de pressão, inclusive psicológica, como insinuações do tipo "se você não doar, fulano (o receptor) vai morrer", deveria ser comunicado à equipe. Todos pacientes referiram ter sido bem esclarecidos sobre o caráter voluntário da doação e nenhum se sentiu pressionado ou coagido a fazê-lo. 
No presente estudo, como em vários outros da literatura internacional, a maioria dos doadores era parentes dos receptores, principalmente de primeiro grau ${ }^{(1,4,16,23)}$. Este dado tem importância na orientação do receptor. A possibilidade de um amigo ser doador é pequena. Na experiência dos autores deste estudo, os poucos doadores não aparentados foram pessoas amigas do receptor, que freqüentemente participavam de reuniões e cultos da sua religião e cuja motivação para doação era salvar a vida, ajudar ou aliviar o sofrimento do paciente.

Apesar da ressecção hepática para doação ser procedimento de grande porte, necessitando incisão ampla, a quase totalidade dos doadores avaliou positivamente o pós-operatório. Entretanto, a maioria referiu que a dor foi pior do que antecipado antes do procedimento. TROTTER et al. ${ }^{(24)}$ também relataram que $2 / 3$ dos seus doadores tiveram maior dor pós-operatória do que eles tinham antecipado. Esses autores observaram, também, que a dor pós-operatória no receptor é menor do que no doador. Algumas explicações têm sido propostas para justificar a maior percepção dolorosa pós-operatória nos doadores. Primeiro, enquanto que a hepatectomia no doador é realizada em indivíduos sadios, a operação no receptor é freqüentemente feita em pacientes com sofrimento e dor crônica que, na maioria das vezes, já foram submetidos a vários procedimentos prévios $^{(23,25)}$. Além do mais, psicologicamente, o receptor tem consciência que a operação é a sua única esperança de vida, enquanto que para o doador, o procedimento é uma opção. Segundo, o corticóide administrado no receptor no período perioperatório pode ter algum efeito benéfico: ele reduz a dor através da diminuição da produção de prostaglandinas, redução da bradicinina tissular e diminuição da liberação de neuropeptídios das terminações nervosas ${ }^{(3,15)}$. Finalmente, é possível que a explicação da equipe de transplante para alguns doadores sobre a intensidade da dor pós-operatória tenha sido insuficiente ou incompleta.

Exceto um, os demais doadores referiram que seriam doadores intervivos novamente. A mudança de opinião desse único doador provavelmente foi devida à ocorrência de sofrimento intenso e de complicações graves no seu pósoperatório imediato. Este paciente apresentou insuficiência de múltiplos órgãos e sistemas, secundária à úlcera péptica perfurada, necessitando internação prolongada na UTI, com risco de morte. Entretanto, todos, inclusive esse doador, eram favoráveis à doação post mortem.
A maioria dos doadores não apresentou modificações ou limitações na sua vida após o procedimento. Entretanto, poucos referiram alterações físicas ou psicológicas, como intolerância alimentar ou piora do relacionamento com o receptor. Essas alterações são inespecíficas e difíceis de se correlacionar com a doação.

Apesar da maioria dos doadores desta série ter obtido suporte financeiro para ajudar a custear as despesas durante o processo de doação, mais da metade teve perdas financeiras com despesas para compra de medicamentos, realização de exames complementares, transporte ou perda de rendimentos pela ausência no trabalho. No Brasil, os custos médicos de avaliação dos doadores são totalmente cobertos pelo Sistema Único de Saúde (SUS) ou por alguns convênios, mas as despesas indiretas e as com medicamentos não-hospitalares não o são. Esta perda financeira pode ser fator limitante importante para obtenção de doadores para receptores carentes, principalmente para os que residem distante dos centros transplantadores pelos custos elevados com transporte e hospedagem durante o processo de avaliação e de recuperação pós-operatória.

Alguns autores descrevem que a hepatectomia para doação do fígado para transplante hepático é operação simples e pode ser realizada com pouco tempo de internação hospitalar, com taxas de complicações mínimas ${ }^{(9,13,14,28)}$. Entretanto, para realização deste procedimento é necessária equipe multidisciplinar com grande experiência em transplante hepático e hepatectomias ${ }^{(1,}$ 8). Além do mais, o procedimento é associado com significante morbidade, inclusive com vários óbitos relatados na literatura ${ }^{(2,6,8,}$ 11). Na experiência, complicações menores, como febre, atelectasia pulmonar e infecção de ferida operatória, foram comuns. Um dos pacientes apresentou risco de morte devido a complicações graves. A possibilidade de complicações potencialmente fatais deve ser claramente explicada aos potenciais doadores.

\section{CONCLUSÕES}

A qualidade de vida não muda após a doação. A quase totalidade dos doadores apresenta boa recuperação e retorna completamente as suas atividades normais poucos meses após a doação. $\mathrm{O}$ aspecto mais negativo da doação é a dor pósoperatória. Complicações pós-operatórias menores são freqüentes e complicações potencialmente fatais podem ocorrer. 
Coelho JCU, Parolin MB, Baretta GAP, Pimentel SK, Freitas ACT, Colman D. Donor quality of life after living donor liver transplantation. Arq Gastroenterol 2005;42(2):83-8.

ABSTRACT - Background. Quality of life of the donor after living donor liver transplantation has not been evaluated in Brazil yet. Aim - To evaluate the quality of live of the donor after living donor liver transplantation. Methods - Of a total of 300 liver transplantations, 51 were of living donors. All donors with less than 6 months of follow-up and those who did not want to participate were excluded from the study. The donors answered a questionnaire contained 28 questions about several aspects of donation. Demographic and clinical data from the donors were also evaluated. Results - Thirty-seven donors were included in the study. Thirty-two were first or second degree relatives of the receptor. Only one donor would not donate again. Twenty-two donors (59\%) experienced more postoperative pain than they had previously anticipated. Return to regular activities occurred in less than 3 months for 21 donors (57\%). Twenty-one donors (57\%) referred financial loss with the donation due to expenses with medications, exams, transportation or lost wages. Thirty-three (89\%) had no modification or limitation in their lives after donation. The most negative aspects of donation were postoperative pain and the presence of a surgical scar. Most postoperative complications resolved with clinical treatment, but severe or potentially fatal complications occurred in two patients. Conclusions - Most donors had good recovery and returned to regular activities few months after donation. The most negative aspect of donation was postoperative pain.

HEADINGS - Quality of life. Liver transplantation. Organ procurement. Living donors.

\section{REFERÊNCIAS BIBLIOGRÁFICAS}

1. Beavers KL, Sandler RS, Fair JH, Johnson MW, Shrestha R. The living donor experience: donor health assessment and outcomes after living donor liver transplantation. Liver Transpl 2001;7:943-7.

2. Beavers KL, Sandler RS, Shrestha R. Donor morbidity associated with right lobectomy for living donor liver transplantation to adult recipients: a systematic review. Liver Transpl 2002;8:110-7.

3. Bisgaard T, Klarskov B, Kehlet H, Rosenberg J. Preoperative dexamethasone improves surgical outcome after laparoscopic cholecystectomy. A randomized double-blind placebo-controlled trial. Ann Surg 2003;238:651-60.

4. Brandhagen D, Fidler J, Rosen C. Evaluation of the donor liver for living donor liver transplantation. Liver Transpl 2003;9(10 Suppl 2):S16-28.

5. Broelsch C. Living donor liver transplantation in adults. Eur J Gastroenterol Hepatol 2003;15:3-6.

6. Brown Jr RS, Russo MW, Lai M, Shiffman ML, Richardson MC, Everhart JE, Hoofnagle JH. A survey of liver transplantation from living adult donors in the United States. N Engl J Med 2003;348:818-25.

7. Carone E, Chapchap P, Pugliese V,Averbach M,Abdalla R, Saad R. Transplante hepático com doador vivo familiar: técnica operatória no doador. Rev Col Bras Cir 1997;24:235-41.

8. Chan SC, Liu CL, Lo CM, Lam CM, Poon RT, Yuen WK, Fan ST, Wong J. Value of live donor liver transplantation experience in major hepatectomy for hepatocellular carcinoma. Arch Surg 2003;138:265-71.

9. Chen YS, Cheng YF, De Villa VH, Wang CC, Lin CC, Huang TL, Jawan B, Chen CL. Evaluation of living liver donors. Transplantation 2003;75(3 Suppl):S16-9.

10. Coelho JCU, Parolin MB, Matias JEF, Cana Jr LW. Causa de óbito tardio em transplantados de fígado. Rev Assoc Med Bras 2003;49:177-80.

11. Crisuwa H, Hashikura Y, Mita A, Miyagawa S-I, Terada M, Ikegami T, Nakazawa Y, Urata K, Ogino S, Karasaki S. Living liver donation: preoperative assessment, anatomic considerations, and long-term outcome. Transplantation 2003;75:1670-6.

12. Diaz GC, Renz JF, Mudge C, Roberts JP, Ascher NL, Emond JC, Rosenthal P. Donor health assessment after living-donor liver transplantation. Ann Surg 2002;236:1206.

13. Ghobrial RM, Saab S, Lassman C, Lu DSK, Raman ST, Limanond P, Kunder G, Marks K, Amersi F, Anselmo D, Chen P, Farmer D, Han S, Han S, Durazo F, Goldstein LI, Busuttil RW. Donor and recipient outcomes in right lobe adult living donor liver transplantation. Liver Transpl 2002;8:901-9.

14. Grewal H, Thistlethwaite J, Loss G, Fisher JS, Cronin DC, Siegel CT, Newell KA, Bruce DS, Woodle ES, Brady L, Kelly S, Boone P, Oswald K, Millis JM. Complications in 100 living-liver donors. Ann Surg 1998;228:214-9.

15. Holte K, Kehler H. Perioperative single-dose glucocorticoid administration: pathophysiologic effects and clinical implications. J Am Coll Surg 2002;195:694-712.
16. Karliova M, Malago M, Valentin-Gomazo C, Reimer J, Treichel U, Franke GH, Nadalin S, Frilling A, Gerken G, Broelsch CE. Living-related liver transplantation from the view of the donor: a 1-year follow-up survey. Transplantation 2002;73:1799-804.

17. Lo CM. Complications and long-term outcome of living liver donors: a survey of 1,508 cases in five Asian centers. Transplantation 2003;75(3 Suppl):S12-5.

18. Parolin MB, Coelho JCU, Igreja M, Pedroso ML, Groth AK, Gonçalves CG. Resultados do transplante de fígado na doença hepática alcoólica. Arq Gastroenterol 2002;39:14752.

19. Pascher A, Sauer IM, Walter M, Lopez-Haeninnen E, Theruvath T, Spinelli A, Neuhaus R, Settmacher U, Mueller AR, Steinmueller T, Neuhaus P. Donor evaluation, donor risks, donor outcome, and donor quality of life in adult-to-adult living donor liver transplantation. Liver Transpl 2002;8:829-37.

20. Raia S, Nery JR, Mies S. Liver transplantation from live donor. Lancet 1989;2:497.

21. Registro Brasileiro de Transplantes 2003;9:16

22. Shiffman ML, Brown Jr RS, Olthoff KM, Everson G, Miller C, Siegler M, Hoofnagle JH. Living donor liver transplantation: summary of a conference at the National Institutes of Health. Liver Transpl 2002;8:174-88.

23. Shrestha R. Psychosocial assessment of adult living liver donors. Liver Transpl 2003;9(10 Suppl 2):S8-11.

24. Trotter JF, Talamantes M, McClure M, Wachs M, Bak T, Trouillot T, Kugelmas M, Everson GT, Kam I. Right hepatic lobe donation for living donor liver transplantation: impact on donor quality of life. Liver Transpl 2001;7:485-93.

25. Trotter JF. Selection of donors for living donor liver transplantation. Liver Transpl 2003(10 Suppl 2):S2-7.

26. UNOS Scientific Registry of Data as of July 23, 2004.

27. Williams RS, Alisa AA, Karani JB, Muiesan P, Rela SM, Heaton ND. Adult-to-adult living donor liver transplant: UK experience. Eur J Gastroenterol Hepatol 2003;15:714.

28. Yamaoka Y, Morimoto T, Inamoto T, Tanaka A, Honda K, Ikai Tanka K, Ichimiya M, Ueda M, Shimahara Y. Safety of the donor in living-related liver transplantation: an analysis of 100 paternal donors. Transplantation 1995;59:224-6. 